\title{
Microbial Lipid Accumulation Capability of Activated Sludge Feeding on Short Chain Fatty Acids as Carbon Sources through Fed-Batch Cultivation
}

Dhan Lord Fortela ${ }^{1}$, Rafael Hernandez ${ }^{1,2 *}$, Mark Zappi ${ }^{1,2}$, Todd W French ${ }^{3}$, Rakesh Bajpai ${ }^{1}$, Andrei Chistoserdov $^{4}$, Emmanuel Revellame ${ }^{2}$ and William Holmes ${ }^{2}$

${ }^{1}$ Department of Chemical Engineering, University of Louisiana, Lafayette, LA 70504, USA

${ }^{2}$ Energy Institute, University of Louisiana, Lafayette, LA 70504, USA

${ }^{3}$ Dave C Swalm School of Chemical Engineering, Mississippi State University, Mississippi State, MS 39762, USA

${ }^{4}$ Department of Biology, University of Louisiana, Lafayette, LA 70504, USA

\begin{abstract}
The potential of activated sludge microbial lipid technology as a sustainable energy platform has been recognized in the past years, but it has been challenged by the cost of carbon sources. This study hypothesized that Short Chain Fatty Acids (SCFAs) that can be derived from organic wastes can be alternative carbon sources. Therefore, this work evaluated the capability of activated sludge microbial consortia to accumulate microbial lipid by fed-batch feeding of SCFAs acetic acid, propionic acid, and butyric acid that were fed every $12 \mathrm{~h}$ period in 5 liter bioreactors. Activated sludge microbial consortia can accumulate microbial lipid by feeding on acetic acid. Acetic acid at $1.5 \mathrm{~g} / \mathrm{L}$ loading per feeding enhanced the lipid content of activated sludge up to around $20 \%(\mathrm{w} / \mathrm{w})$ dry biomass. This is comparable to that of oleaginous microorganisms. The feeding of nitrogen source (ammonium) at molar $\mathrm{C} / \mathrm{N}$ of 70 only at the start resulted in significant lipid accumulation as compared to that from feeding of nitrogen for every feeding of the carbon source (acid-substrates). Fatty Acid Methyl Esters (FAMEs) profiles of the extracted lipids changed during cultivation. A biodiesel volumetric yield increase of $325 \%(\mathrm{w} / \mathrm{w})$ from initial culture was achieved. This microbial lipid enhancement was confirmed using fluorescence microscopy imaging of neutral lipids, which also showed that the neutral lipid-containing cells are in the size range of yeasts. This work proved the hypothesis that activated sludge microbial consortia can accumulate microbial lipid by feeding on SCFAs.
\end{abstract}

Keywords: Microbial lipid; Biodiesel; Activated sludge; Short chain fatty acids; Fed-batch cultivation

\section{Introduction}

Previous studies have demonstrated that the mixed microbial consortium in the activated sludge generated during wastewater treatment has the metabolic capability to accumulate lipid (triglycerides) when grown under a high carbon nitrogen ratio [14]. The carbon sources used in these studies were glucose and xylose. The process was envisioned as a novel platform for the production of biodiesel and specialty chemicals from waste activated sludge [14]. However, the economic feasibility of the system is challenged by the relatively high cost of carbon sources, especially refined monosaccharides. Several studies explored the use of Short Chain Fatty Acids (SCFAs) such as acetic acid, propionic acid and butyric acid as alternative substrates for oleaginous single cultures [5-7]. By definition oleaginous microorganisms can accumulate more than $20 \%$ of the cell dry weight as lipids. These SCFAs could be cost-effective because they are intermediate compounds during anaerobic digestion, also a wellestablished process in wastewater treatment [8]. Anaerobic digestion and activated sludge could be integrated to produce microbial lipids. Further Park et al. [9] used various data from the literature in a simulation study and found several economic benefits of using SCFAs from organic wastes to produce microbial lipid and biodiesel.

Amid the potential advantages, these SCFAs still pose a challenge as they have inhibitory effects on microorganisms in activated sludge. A previous work [10] shows that acetic acid, propionic acid and butyric acid inhibit activated sludge with almost complete inhibition at SCFAs loading higher than $5 \mathrm{~g} / \mathrm{L}$. The researchers found that the mass ratio of the acids is a significant factor in the chemical inhibition, and that operating at near-neutral $\mathrm{pH}$ ranges is less inhibitory. Mondala et al. [11] observed that acetic acid enhanced batch biomass production of glucose-fed activated sludge at acetic acid loading of $10 \mathrm{~g} / \mathrm{L}$, but reduced lipid production.

An operational technique that has been tested to reduce chemical inhibition on microbial lipid accumulation is the fed-batch mode as it promotes acclimation period and gradual feeding when using a substrate that is inhibitory at high loadings. Fei et al. [12], du Preez et al. [13] and du Preez et al. [14] demonstrated that fed-batch operation of a bioreactor improves lipid accumulation over that of a batch operation of a pure oleaginous microbial cultures feeding on SCFAs. This operational mode was also used to conduct high cell density culture to improve microbial lipid yield in other oleaginous cultures $[15,16]$.

Therefore, this study evaluated the capability of wastewater activated sludge microorganisms to accumulate lipid by feeding on SCFAs such as acetic acid, propionic acid, and butyric acid under fedbatch operation in 5-L bioreactors. Samples were collected over the period of fed-batch incubation to monitor the biomass growth, acidsubstrate utilization, ammonium-N utilization, and microbial lipid accumulation. Extracted microbial lipid of each sample was transesterified to determine fatty acid profile.

*Corresponding author: Rafael Hernandez, Department of Chemical Engineering University of Louisiana at Lafayette, PO Box 44130, Lafayette, LA 70504-4130, USA, Tel: 337-482-6062; E-mail: rhernandez@louisiana.edu

Received March 16, 2016; Accepted April 11, 2016; Published April 15, 2016

Citation: Fortela DL, Hernandez R, Zappi M, French TW, Bajpai R, et al. (2016) Microbial Lipid Accumulation Capability of Activated Sludge Feeding on Short Chain Fatty Acids as Carbon Sources through Fed-Batch Cultivation. J Bioprocess Biotech 6: 275. doi:10.4172/2155-9821.1000275

Copyright: (c) 2016 Fortela DL, et al. This is an open-access article distributed under the terms of the Creative Commons Attribution License, which permits unrestricted use, distribution, and reproduction in any medium, provided the original author and source are credited. 


\section{Materials and Methods}

\section{Sample activated sludge inoculum}

Activated sludge microorganism samples were taken from the return sludge stream of the oxidation ditch of the East Wastewater Plant (WWTP), Lafayette, Louisiana 70501 USA (Map: 30¹2'59"N, $\left.92^{\circ} 00^{\prime} 03^{\prime \prime} \mathrm{W}\right)$. With a short travel time from the WWTP to the laboratory after sampling, the grab sludge samples were immediately processed for the experiments.

\section{Fed-batch bioreactor experiments}

Fed-batch cultures in the synthetic wastewater were performed in two 5-L bioreactors (BIOFLO 3000, New Brunswick ScientificEppendorf, Edison, NJ). The following physical conditions were maintained in all the bioreactor runs: temperature at $25^{\circ} \mathrm{C}$, agitation at $200 \mathrm{rpm}$, and aeration at $1 \mathrm{vvm}$ (volume air per volume culture per minute). The $\mathrm{pH}$ was not controlled but monitored. The working volume for each reactor was 4 liters.

The media used for the fed-batch bioreactor experiments is a synthetic wastewater (SWW) prepared fresh for each run with chemical composition similar to that used by Mondala et al. [17] (in $\mathrm{L}^{-1}$ deionized water): $0.15 \mathrm{~g}$ gelatin, $0.21 \mathrm{~g}$ starch, $0.07 \mathrm{~g}$ yeast extract, 0.01 g casamino acids, $1.5 \mathrm{~g} \mathrm{NaH}_{2} \mathrm{PO}_{4}, 1 \mathrm{~g} \mathrm{~K}_{2} \mathrm{HPO}_{4}$, and $5 \mathrm{~mL}$ trace minerals solution. The trace minerals solution has the following composition (in $\mathrm{L}^{-1}$ deionized water): $0.5 \mathrm{~g}$ ethylenediaminetetraacetic acid (EDTA), 3 $\mathrm{g} \mathrm{MgSO}_{4} \cdot 7 \mathrm{H}_{2} \mathrm{O}, 0.5 \mathrm{~g} \mathrm{MnSO}_{4} \cdot \mathrm{H}_{2} \mathrm{O}, 1 \mathrm{~g} \mathrm{NaCl}, 0.1 \mathrm{~g} \mathrm{FeSO}_{4} \cdot 7 \mathrm{H}_{2} \mathrm{O}, 0.1 \mathrm{~g}$ $\mathrm{CaCl}_{2}$ anhydrous, $0.1 \mathrm{~g} \mathrm{ZnSO}_{4} \cdot 7 \mathrm{H}_{2} \mathrm{O}$ and $0.01 \mathrm{~g} \mathrm{CuSO}_{4} \cdot 5 \mathrm{H}_{2} \mathrm{O}$.

Prior to culture run, the grab sample of activated sludge was centrifuged to separate the solids. The liquid phase was discarded. The amount of recovered solids from the grab sludge sample after centrifugation was added to $3 \mathrm{~L}$ of synthetic wastewater. A previous volume displacement experiment established the amount of recovered solids needed to achieve a solids concentration of the synthetic wastewater of $13-14 \mathrm{~g} / \mathrm{L}$ in all the runs. The experimental treatments are summarized in Table 1 . The conditions in these treatments were specified to test key aspects of the fed-batch cultivation on SCFAs. The substrates used were acetic acid, propionic acid, and butyric; and the $\mathrm{N}$-source was ammonium sulfate. The parameters varied were acid-substrate composition, ammonium sulfate feeding to vary feed $\mathrm{C} / \mathrm{N}$ ratio, and the culture media. A $\mathrm{pH}$ buffer system comprised of 3-(N-morpholino)-propanesulfonic acid (MOPS) was also tested. The feeding of the acid substrates was at 12 hour intervals at which culture samples were also collected before and after substrate feeding.

\section{Analytical methods}

Cell biomass concentration was measured gravimetrically. The culture samples were centrifuged at $3000 \mathrm{~g}$ for 20 minutes. Then cell pellets were washed with $20 \mathrm{~mL} 2.5 \%$ saline solution and stored in a $-80^{\circ} \mathrm{C}$ freezer for 24 hours. The frozen cell pellets were freezedried for 48 hours and the dried solids were weighed. The results were reported as cell dry mass concentration. Residual SCFAs in the supernatant were measured using liquid chromatography. Ammonium was measured using ion chromatography and $\mathrm{Hach} \mathrm{NH}_{3}-\mathrm{N}$ salicylate reagent kit. Biomass-associated lipids were extracted in accelerated solvent extraction (ASE) equipment using chloroform-methanol (35\% $\mathrm{v} / \mathrm{v}$ methanol to $65 \% \mathrm{v} / \mathrm{v}$ chloroform) solvent system. The extracts were transferred into pre-weighed $40 \mathrm{~mL}$ ASE vials. The methanol and chloroform in the extracts were evaporated in an automated high speed evaporator by purging nitrogen and maintaining temperature at $60^{\circ} \mathrm{C}$. The gravimetric lipid yields were determined by weight difference. Fatty Acid Methyl Ester (FAME) profile and biodiesel yield of the lipid extracts were analyzed using the procedure applied by Mondala et al. [3].

\section{Confocal microscopy}

Fluorescence images of the raw activated sludge and the lipidenhanced activated sludge (Treatment 4) were collected using Leica SP5 confocal-laser-scanning microscope (Leica Microsystems). The culture samples $(20 \mathrm{~mL})$ were centrifuged for $10 \mathrm{~min}$ at $3000 \mathrm{~g}$ and the liquid portion discarded, while portions of the wet residue of samples were weighed into the staining tubes to make approximately the same solids concentration $(10 \mathrm{mg} / \mathrm{mL})$ in staining mixture. The microbial cells were stained with BODIPY 493/503 (Molecular Probes, Invitrogen), which was dissolved in ethanol at $1 \mathrm{mg} / \mathrm{mL}$ and used at 1 $\mu \mathrm{g} / \mathrm{mL}$ by dilution with Phosphate-Buffered Saline (PBS) $1 \mathrm{X}$ solution. The staining was done for 30 minutes in the dark at room temperature; afterwards the cells were washed with PBS $1 \mathrm{X}$ and re-suspended in PBS $1 \mathrm{X}$ prior to slides preparation.

\section{Results}

The fed-batch cultivation results under the various treatments (Table 1) are summarized in Figures 1 and 2. The key aspects tested through these treatments are presented in the following subsections (Figure 3). The fluorescence microscopy images of a set of raw and lipid-enhanced activated sludge's are shown in Figure 4.

\section{Utilization of short chain fatty acids}

The utilization of the three acids acetic acid, propionic acid, and butyric acid was evaluated using treatment 1 (Figures $1 \mathrm{~A}-1 \mathrm{G}$ ). There was no significant consumption of the three acids for the first 24 hours of incubation. Thereafter, the acids were consumed with acetic acid having the highest utilization followed by butyric acid. Propionic acid was consumed slightly. Towards the end of the fifth day of incubation, both propionic and butyric acid maintained a steady concentration in the system. These data indicated that a short chain SCFA is preferred by activated sludge microorganisms over the long chain acids. The data

\begin{tabular}{|c|c|c|c|c|}
\hline Treatment No. & Acid substrate & Acid substrate loading every 12 hours & Feed molar $\mathrm{C} / \mathrm{N}$ ratio & Culture media \\
\hline 1 & Acetic acid, propionic acid, butyric acid & $1.5 \mathrm{~g} / \mathrm{L}$ total at $1: 1: 1$ mass ratio & 70 every feeding & SWW \\
\hline 2 & Acetic acid & $1.5 \mathrm{~g} / \mathrm{L}$ & 70 every feeding & SWW \\
\hline 3 & Acetic acid & $1.5 \mathrm{~g} / \mathrm{L}$ & 70 at time $0 \mathrm{~h}$ & SWW \\
\hline 4 & Acetic acid & $1.5 \mathrm{~g} / \mathrm{L}$ & 70 at time $0 \mathrm{~h}$ & $\begin{array}{l}\text { SWW+sodium acetate } \\
\text { every feeding to buffer } \\
\text { acetic acid (equimolar, } \\
\text { target } \mathrm{pH}=\mathrm{pKa}=4.76)\end{array}$ \\
\hline 5 & Acetic acid & $1.5 \mathrm{~g} / \mathrm{L}$ & 70 at time $0 \mathrm{~h}$ & $\begin{array}{l}\text { SWW in } 5 \text { X MOPS buffer } \\
\text { set at } \mathrm{pH} 7.2\end{array}$ \\
\hline 6 & Acetic acid & $3 \mathrm{~g} / \mathrm{L}$ & 140 at time $0 \mathrm{~h}$ & $\begin{array}{c}\text { SWW in 5X MOPS buffer } \\
\text { set at } \mathrm{pH} 7.2\end{array}$ \\
\hline
\end{tabular}

Table 1: Experimental treatment conditions in the fed-batch runs. 
Treatment 1

Acetic, propionic, butyric mix $1.5 \mathrm{~g} / \mathrm{L}$ total (1:1:1 mass ratio) $70 \mathrm{C} / \mathrm{N}$ ratio every loading SWW media
Treatment 2

Acetic acid

$1.5 \mathrm{~g} / \mathrm{L}$ per loading

$70 \mathrm{C} / \mathrm{N}$ ratio every loading SWW media
Treatment 3

Acetic acid

$1.5 \mathrm{~g} / \mathrm{L}$ per loading

$70 \mathrm{C} / \mathrm{N}$ ratio at $\mathrm{t}=0 \mathrm{~h}$

SWW media

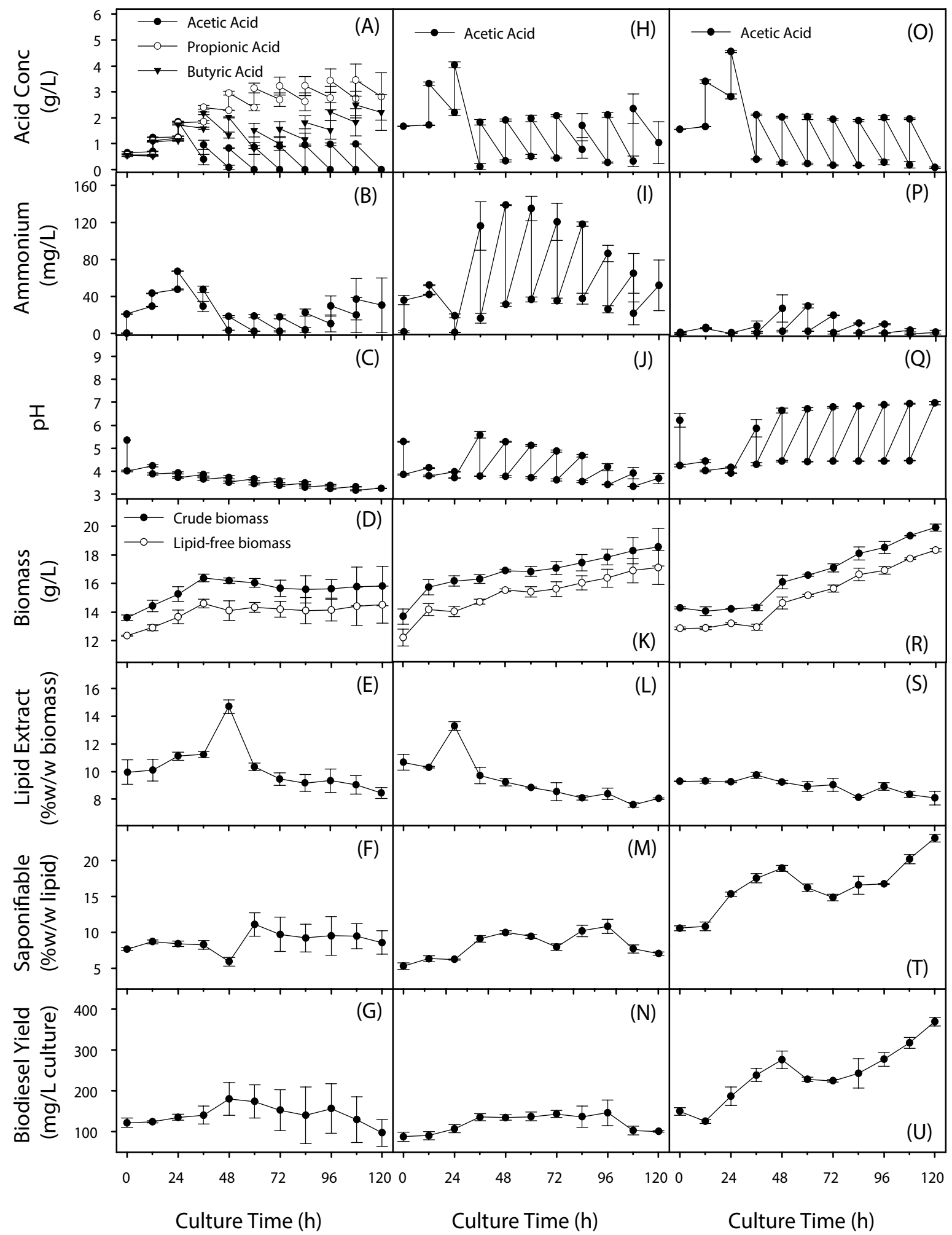

Figure 1: Microbial lipid accumulation of activated sludge microbial consortia under various carbon loading, nitrogen loading, and culture media conditions: Treatments 1-3. 
Treatment 4

Acetic acid-acetate buffer $1.5 \mathrm{~g} / \mathrm{L}$ per loading

$70 \mathrm{C} / \mathrm{N}$ ratio at $\mathrm{t}=0 \mathrm{~h}$ SWW media
Treatment 5

Acetic acid

$1.5 \mathrm{~g} / \mathrm{L}$ per loading

$70 \mathrm{C} / \mathrm{N}$ ratio at $\mathrm{t}=0 \mathrm{~h}$

SWW in 5X MOPS media
Treatment 6

Acetic acid

$3 \mathrm{~g} / \mathrm{L}$ per loading

$140 \mathrm{C} / \mathrm{N}$ ratio at $\mathrm{t}=0 \mathrm{~h}$

SWW in $5 X$ MOPS media
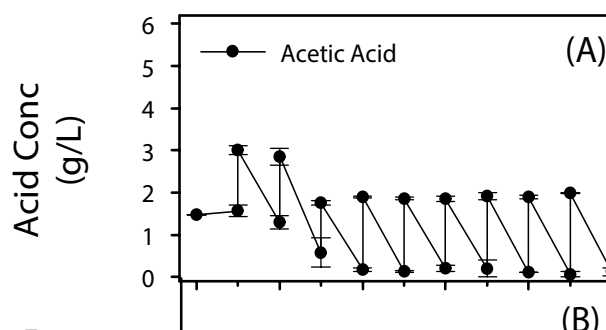

(A) - Acetic Acid

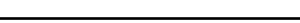

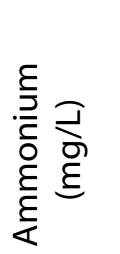

I

(B)

(l)

\section{B)}

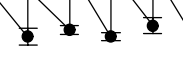

$1 \geq$

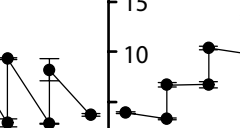

(P)

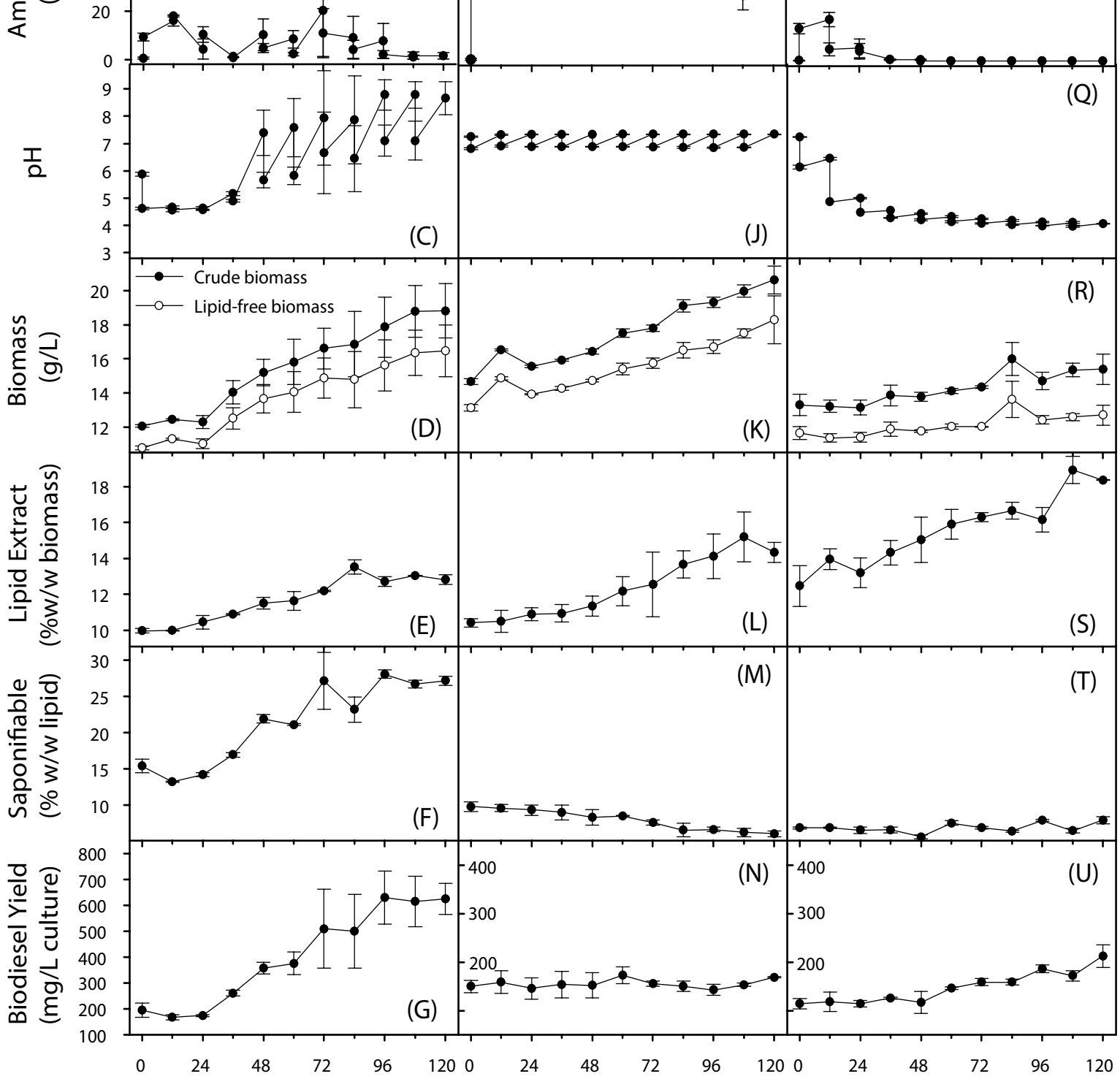

Culture Time (h)

Culture Time (h)

Culture Time (h)

Figure 2: Microbial lipid accumulation of activated sludge microbial consortia under various carbon loading, nitrogen loading, and culture media conditions: Treatments 4-6. 


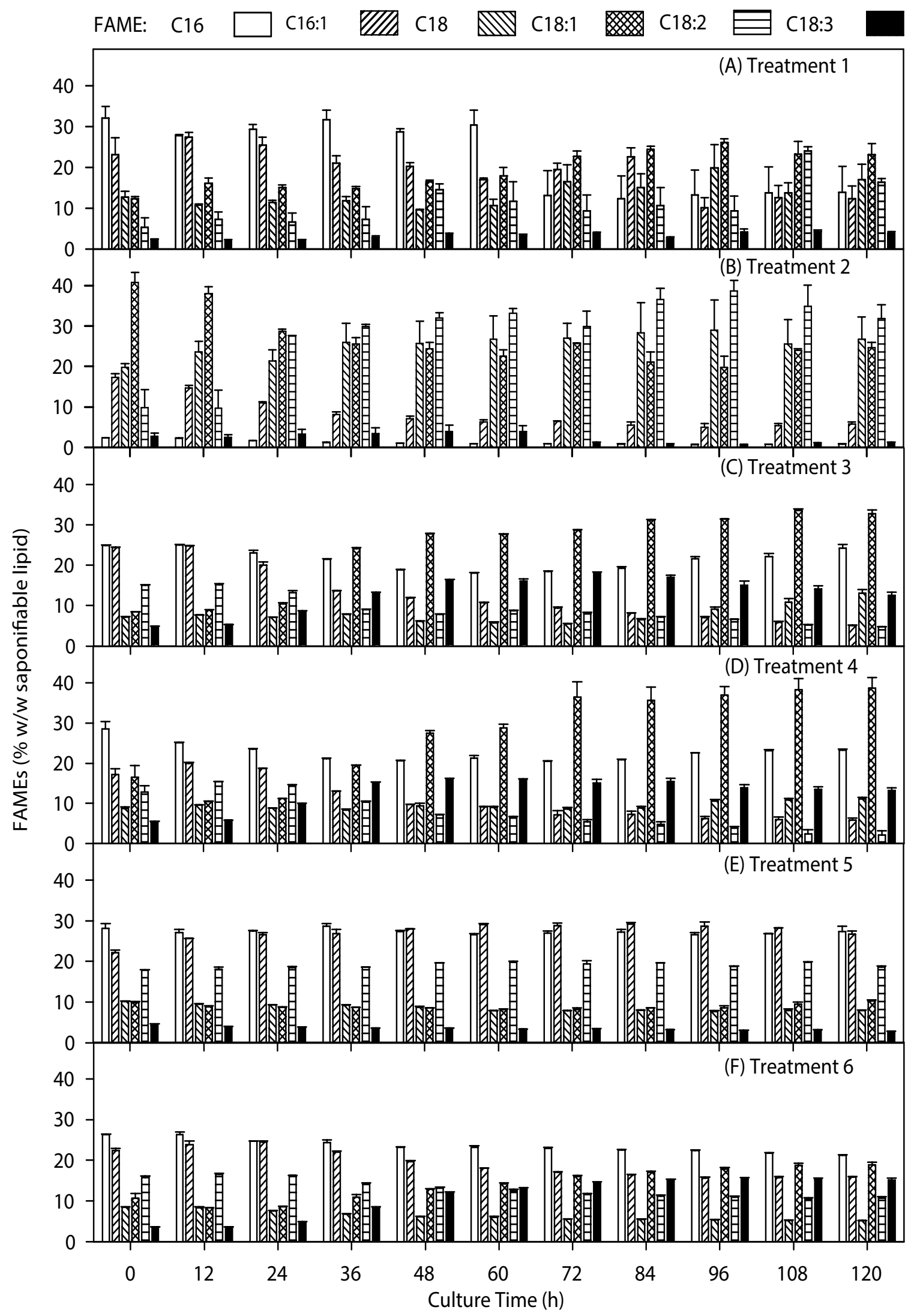

Figure 3: Profiles of FAMEs from the microbial lipid extracts of the fed-batch runs. 
Citation: Fortela DL, Hernandez R, Zappi M, French TW, Bajpai R, et al. (2016) Microbial Lipid Accumulation Capability of Activated Sludge Feeding on Short Chain Fatty Acids as Carbon Sources through Fed-Batch Cultivation. J Bioprocess Biotech 6: 275. doi:10.4172/2155-9821.1000275

(A)

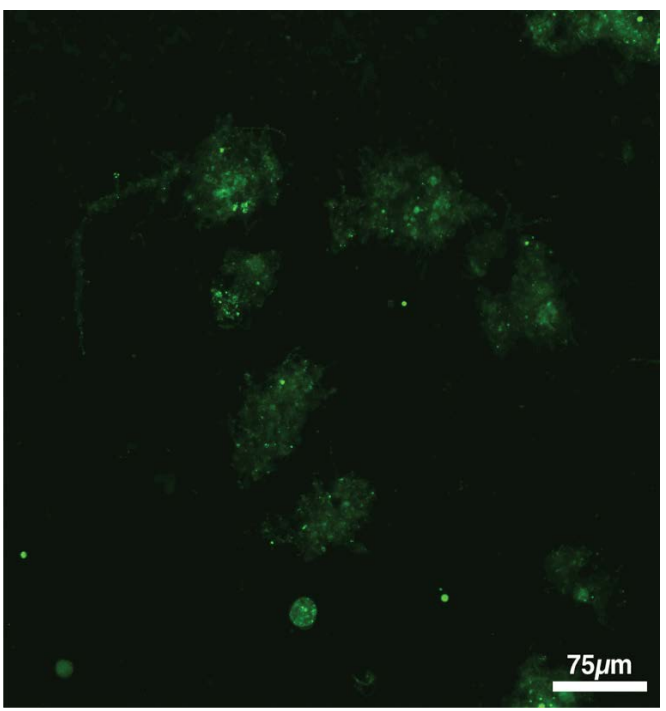

(C)

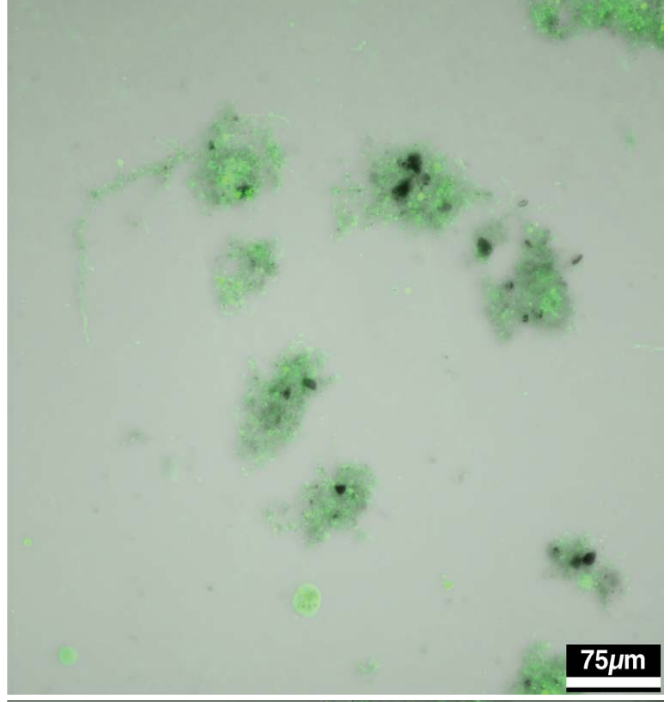

(E)

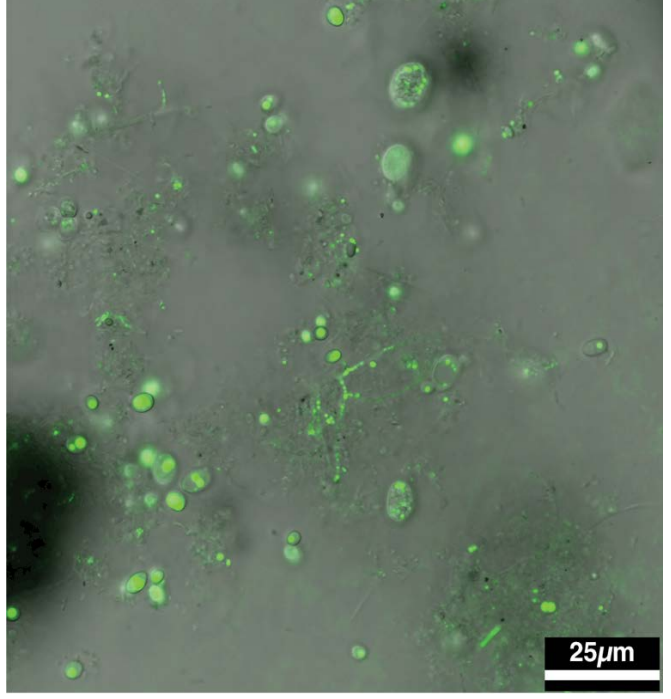

(B)

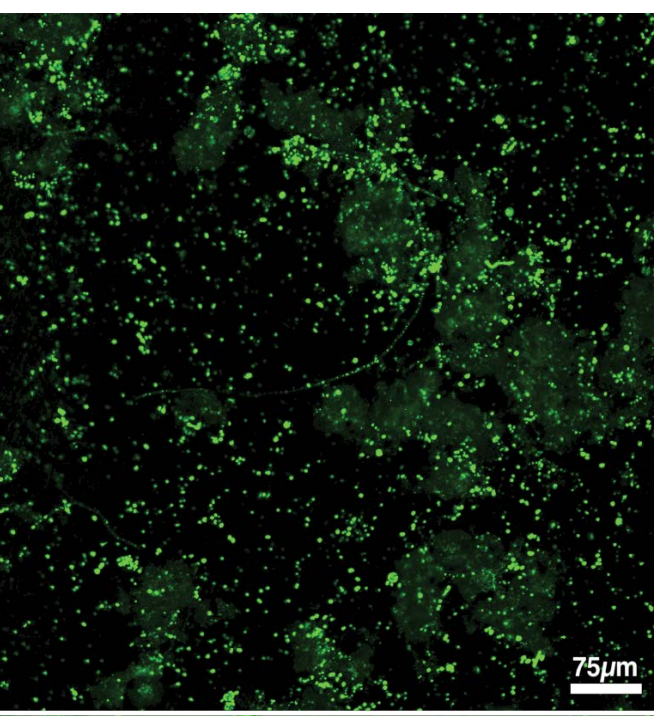

(D)

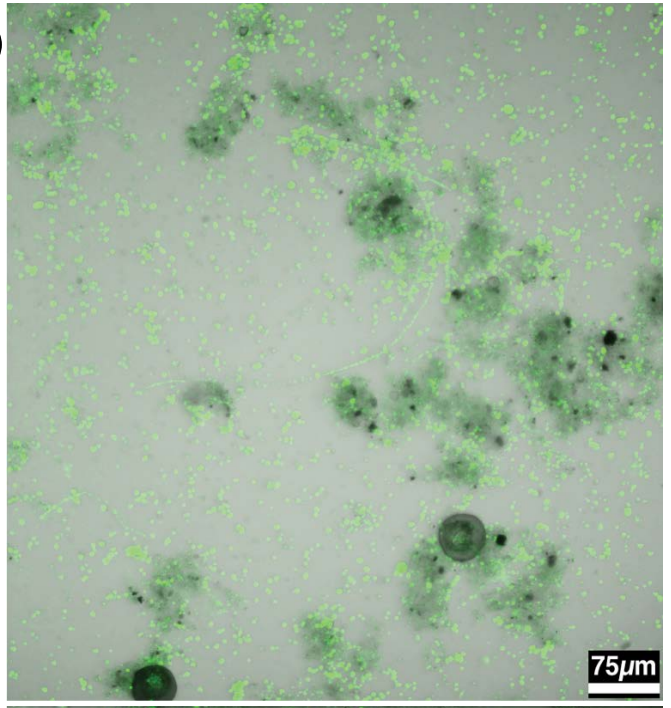

(F)

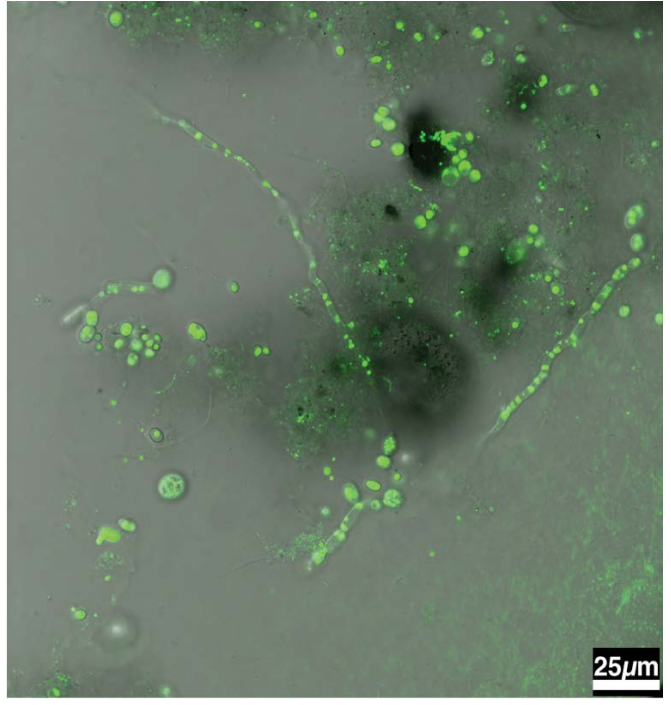

Figure 4: Confocal microscopy images of samples taken from the cultivation of activated sludge (AS) under feeding of acetic acid-sodium acetate buffer system (treatment 4): (A) fluorescence image of the raw AS; (B) fluorescence image of the final lipid-enhanced AS; (C) overlay of fluorescence and transmitted light images of raw AS; (D)-(F) overlay of fluorescence and transmitted light images of final lipid-enhanced AS at varying magnification and location. 
suggest that SCFAs with even number of carbon atoms are preferred over fatty acids with odd number of carbon atom.

When only acetic acid was fed in Treatment 2 (Figures $1 \mathrm{H}-1 \mathrm{~N})$, the acid was consumed after 12 hour incubation, which is 12 hours earlier than that of Treatment 1 . The $\mathrm{pH}$ was also able to increase nearer to neutral level every fed-batch cycle after the first 24 hours. These conditions resulted to monotonous increase in biomass concentration (Figure $1 \mathrm{~K}$ ) and suggested that feeding only acetic acid is better for biomass growth as compared to feeding with a mix of acetic acid, propionic acid, and butyric acid.

\section{Effect of feed nitrogen loading}

Since $\mathrm{C} / \mathrm{N}$ ratio is an important parameter in the lipid accumulation of microorganisms, two nitrogen feeding modes were tested - (1) ammonium feeding per acid-substrate feeding done in Treatments 1 and 2; and (2) ammonium feeding only at the start of the fed-batch run done in Treatments 3, 4, 5 and 6 . In general, the fed-batch runs with ammonium feeding only at the start of each run (Treatments 4-6) enhanced the lipid content at the end of 5-day incubation, while the runs with ammonium feeding per acid-substrate feeding (Treatments 1 and 2) contained lower amount of lipid at the end of incubation. Even though Treatments 1 and 2 resulted in lower lipid content and the end of the incubation period, there were temporary increases in the activated sludge lipid contents. Treatment 1 had a temporary maximum lipid increase after 36 hours, while Treatment 2 had a temporary maximum lipid content at after 24 hours. The gradual decrease of lipid content after these maximums may be due to the presence of high amounts of residual ammonium in the culture. Treatment 3 was run as a counterpart run of Treatment 2 to initially test the effect of decreasing the loading of ammonium; hence, increasing the $\mathrm{C} / \mathrm{N}$ ratio in the system. A lag phase for biomass growth occurred for 36 hours (Figure $1 \mathrm{R})$. The lipid content was not enhanced even at higher $\mathrm{C} / \mathrm{N}$ ratio (Figure 1S), but the saponifiable lipid fraction significantly increased resulting in higher volumetric biodiesel yield as compared to that of Treatment 2 (Figures $1 \mathrm{M}$ and $1 \mathrm{~N}$ ).

\section{Effect of pH buffer system}

The $\mathrm{pH}$ of culture media is a significant factor in lipid accumulation [7], so the effect of $\mathrm{pH}$ in fed-batch cultivation must be tested. Since acetic acid is a weak acid and can make a buffer system with a conjugate base salt, sodium acetate was added to the feed acetic acid to make a buffer around $\mathrm{pH} 4.76$, which maximizes the buffer capacity since this is the pKa of acetic acid. This addition of acetic acid-acetate buffer is done in Treatment 4 (Figures $2 \mathrm{~A}-2 \mathrm{G}$ ). All the acetic acid was consumed after a 24 hour lag phase (Figure 2D). The lipid content increased (Figure 2E) with a corresponding increase in the saponifiable fraction (Figure 2F). The volumetric biodiesel yield increased to around $325 \%$ as compared to the initial culture (Figure $2 \mathrm{G}$ ).

Another $\mathrm{pH}$ buffer system tested was a MOPS buffer, which was shown to be chemically inert towards microbial cultures. The MOPS buffer that was set at $\mathrm{pH} 7.2$ with strength of $5 \mathrm{X}$ was used in Treatments 5 and 6 . The resulting $\mathrm{pH}$ from the loading of $1.5 \mathrm{~g} / \mathrm{L}$ in Treatment 5 was buffered around 7 by the MOPS system. This resulted in the highest biomass concentration of around $21 \mathrm{~g} / \mathrm{L}$ (Figure $2 \mathrm{~K}, \mathrm{t}=120 \mathrm{~h}$ ) among all the treatments. On the other hand, the $\mathrm{pH}$ from the loading of $3 \mathrm{~g} / \mathrm{L}$ (Treatment 6) was not buffered by the MOPS buffer system even just after the first acid-substrate feeding (Figure 2Q). The buffer system was consumed with the further addition of acetic acid, resulting to lower biomass growth (Figure 2R) as compared to Treatment 5 (Figure $2 \mathrm{~K}$ ).
Nonetheless, the final lipid content from Treatment 6 was the highest of the entire lipid extracted and was around $20 \% \mathrm{w} / \mathrm{w}$ which is within the range the lipid content of pure cultures that are considered oleaginous [7]. A common feature of these two treatments buffered using MOPS was that the saponifiable fractions of lipid extracts were not increased (Figures $2 \mathrm{M}$ and $2 \mathrm{~T}$ ); hence, there was insignificant increase in the volumetric biodiesel yield of these runs (Figures $2 \mathrm{~N}$ and $2 \mathrm{U}$ ).

\section{Effect of acid-substrate loading}

Previous works showed the potential of high acid loading to inhibit the growth of activated sludge microorganisms in batch cultivation. To test the effect of acid loading on activated sludge in fed-batch cultivation, the acid-substrate loading was set at $1.5 \mathrm{~g} / \mathrm{L}$ and $3 \mathrm{~g} / \mathrm{L}$ in Treatments 5 and 6, respectively. The biomass growth in Treatment 5 (Figure $2 \mathrm{~K}$ ) was significantly higher than the biomass growth in Treatment 6 (Figure 2R) with acid loading twice that of Treatment 5. The consumption of acetic acid is higher for the acid loading at $1.5 \mathrm{~g} / \mathrm{L}$ (Figure $2 \mathrm{H}$ ) than that at $3 \mathrm{~g} / \mathrm{L}$ (Figure 2O). These patterns indicate the possible occurrence of growth inhibition at higher acid loading even under fed-batch feeding of acetic acid. Acid loading also has significant effect on the lipid content. Treatment 6 resulted in significantly higher lipid content at the end of incubation (Figure 2S) as compared to that of Treatment 5 (Figure 2L). This trend manifests the tendency of the microorganisms to accumulate more lipids at higher $\mathrm{C} / \mathrm{N}$ ratio, which in this case the initial feed molar $\mathrm{C} / \mathrm{N}$ for Treatment 6 is 140 as compared to the initial feed molar $\mathrm{C} / \mathrm{N}$ of 70 in Treatment 5 . These opposing trends in biomass growth and lipid accumulation as the acid loading is increased must be considered in finding optimum acidsubstrate loading.

\section{Profile of lipid FAMEs derivatives}

The fatty acid methyl ester (FAME) derivatives profile of the lipid extracts from the treatment runs are shown in Figure 3. In general, the FAMEs profiles in all the runs change to run-specific profiles at the end of five-day incubation. The cultivation under feeding of mix acetic acid, propionic acid and butyric acid with a corresponding addition of the nitrogen source, ammonium sulfate, per feeding (Treatment 1) decreased the amounts of palmitic acid (C16:0) and palmitoleic acid (C16:1) while increasing the amounts of stearic acid (C18:0), oleic acid (C18:1), and linoleic acid (C18:2) (Figure 3A). Using only acetic acid per feeding with a corresponding ammonium loading (Treatment 2) had the result of decreasing C16:1, increasing C18:0, decreasing C18:1 and increasing C18:2 (Figure 3B). Feeding only acetic acid with feeding of ammonium only at the start of the run (Treatments 3 and 4) maintained high fraction of C16:0, increased fractions of $C 18: 1$ and linoleic acid (C18:3) (Figures 3C and 3D). The runs under MOPS buffer system (Treatments 5 and 6) maintained high fractions of C16:0 and C16:1, but the fractions of the C18's varied between these treatments. Treatment 5 (Figure 3E) with a $1.5 \mathrm{~g} / \mathrm{L}$ acetic acid loading per feeding maintained almost the same fraction of C18:0, C18:1, C18:2 and C18:3 throughout the run while Treatment 6 (Figure 3F) with $3 \mathrm{~g} / \mathrm{L}$ acetic acid loading per feeding increased fractions of both $\mathrm{C} 18: 1$ and C18:3 while decreasing fraction of C18:2.

\section{Fluorescence microscopy analysis of neutral lipids}

To verify the enhancement of lipid content of activated sludge, fluorescence microscopy imaging was done after staining the culture samples taken from Treatment 4 with fluorescent neutral lipid-staining dye BODIPY 493/503 (Invitrogen) and the results are shown in Figure 4. There were neutral lipids in the raw activated sludge (AS) sample as 
indicated by the bright green regions (Figures $4 \mathrm{~A}$ and $4 \mathrm{C}$ ). By the end of the cultivation, the number of lipid droplets increased significantly (Figures 4B and 4D) confirming the enhancement of lipid content of AS. These lipid droplets were within the microbial cells as shown in higher magnification images in Figures $4 \mathrm{E}$ and $4 \mathrm{~F}$. There were various morphological structures in the samples supporting the fact that AS contains a consortia of microorganisms. Microbial community analyses of activated sludge done in previous works $[18,19]$ showed that various bacterial and fungal species dominate depending on the chemical composition of nutrients in the culture (Figures 1-4).

\section{Discussion}

Previous studies showed that microbial lipid in activated sludge microorganisms can be a potential alternative route to produce biodiesel and other value-added chemicals [20,21]. Low lipid yields prompted the search for improvements on the technology $[4,11,17,22$ 25]. Since the main requirement of the technology is a high carbonto-nitrogen ratio $(\mathrm{C} / \mathrm{N})$ to trigger enhancement of microbial lipid content, a major challenge to economic feasibility is cost of the carbon source. The easily assimilable carbon sources glucose and xylose [3] are costly, so the search and testing for alternate carbon sources have been the focus of succeeding studies including this work. A proposition adoptable to the context of resource recovery from wastewater is the use of Short Chain Fatty Acids (SCFAs) such as acetic acid, propionic acid and butyric acid as carbon sources [8]. The hypothesis of this study is that SCFAs can be carbon sources for activated sludge microbial lipid accumulation. The results of this work proved this hypothesis.

Acetic acid is preferred to propionic acid and butyric acid as carbon source by activated sludge (Figures $1 \mathrm{~A}$ and $1 \mathrm{H}$ ). The presence of propionic acid and butyric acid repressed the growth of biomass, which was evident when Figures $1 \mathrm{D}$ and $1 \mathrm{~K}$ were compared. When the three SCFAs were fed (Treatment 1), the biomass growth stopped with further accumulation of propionic acid and butyric acid after 24 hours of incubation (Figure 1D). When propionic acid and butyric acid were removed from the feed (Treatment 2), the biomass growth was monotonously increasing. Though this finding imposes constraint on the desirable composition of feed SCFAs, the anaerobic digester, which is the potential source of SCFAs in a wastewater treatment plant (WWTP), typically contains very high amounts of acetic acid relative to the other organic acids such as propionic and butyric [26,27]. Previous work showed that anaerobic digestion of cellulose produces acetic acid at $60 \%-70 \% \mathrm{w} / \mathrm{w}$ total organic acids with acetic acid concentration of around $1.5 \mathrm{~g} / \mathrm{L}$ after 36 hours [28]. This is advantageous for the envisioned industrial-scale integration of the technology with existing WWTPs as the stream containing SCFAs will not require enrichment of acetic acid fraction and stripping of the other organic acids that are present at a lower concentration.

Another process design constraint must then be considered with regards to the finding that feeding nitrogen (ammonium) source only at the start of the run (Treatments 3 to 6 ) is more desirable over feeding of nitrogen source per feeding of carbon source (Treatments 1 and 2) in terms of biomass and lipid content under fed-batch cultivation. The typical concentration of ammonium in average strength raw influent wastewaters into a WWTP is in the range $12-50 \mathrm{mg} / \mathrm{L}$, which corresponds to the concentration of ammonium $(40 \mathrm{mg} / \mathrm{L})$ necessary to achieve $\mathrm{C} / \mathrm{N}$ of 70 at $1.5 \mathrm{~g} / \mathrm{L}$ acetic acid loading per feeding. Since a $\mathrm{C} / \mathrm{N}$ of 70 only at the start is more desirable than a $\mathrm{C} / \mathrm{N}$ of 70 per feeding of SCFAs (every $12 \mathrm{~h}$ period) for an entire fed-batch run, there must be a way to control the concentration of nitrogen-containing compounds (such as ammonia) going to the lipid accumulation section of an anaerobic digestion-aerobic lipid accumulation system.

The highest lipid contents were from the cultures run with MOPS buffer, and the levels of accumulated lipids are comparable to the results of batch co-fermentation of glucose and xylose by activated sludge culture done by Mondala et al. [3]. This is the first demonstration that even a potential inhibitory carbon source such as acetic acid can be a suitable feed comparable in performance to monosaccharide substrates. Clearly, the $\mathrm{pH}$ level significantly affects the growth of activated sludge microbial consortia. Acetate ion $\left(\mathrm{CH}_{3} \mathrm{COO}^{-}\right)$has the same metabolic potential as sugars. Table 2 summarizes the calculated biomass yields from the various treatments. The variation of the lipid content and saponifiable lipid fraction depending on the treatment implies that trade-offs exist over the desired value-added products (Treatments $3,4,5$ and 6). Though saponifiable lipids are precursors to biodiesel production, the non-saponifiable lipids are valuable as well. Waxes and polyesters are microbial lipids that many bacteria usually accumulate in significant amounts and that are now becoming commercially viable [29]. So, the target end-product must be considered in specifying the cultivation conditions under acetic acid feeding.

With biodiesel as one of the target end-products of microbial lipid, the total yield and composition of the FAMEs derived from the lipid extracts might also play an important role in considering the cultivation conditions with SCFAs. The high volumetric yields of biodiesel (as total FAMEs) were obtained during Treatments 3 (Figure $1 \mathrm{U}$ ) and 4 (Figure $2 \mathrm{G}$ ), which were run under $1.5 \mathrm{~g} / \mathrm{L}$ loading of acetic acid with ammonium loading only at the start of the run. Treatment 3 is peculiar because the saponifiable fraction of the extracted lipid increased even though the lipid content of the biomass did not increase (Figure 1S). This may signify either the conversion of non-saponifiable lipids into saponifiable lipids, or the accumulation of lipids from acetic acid at the expense of non-saponifiable lipids degradation. As of the moment, there is no available literature to support a concrete theory for this observation. This trend is in contrast with the trends of the runs in MOPS buffer (Treatments 5 and 6 ) in which biodiesel volumetric yield did not significantly increase (Figure $2 \mathrm{~N}$ and $2 \mathrm{U}$ ) even with increase in the biomass lipid content. These trends suggest that feeding acetic acid without buffering at near neutral $\mathrm{pH}$ is preferable if the target endproduct is biodiesel.

Change in the FAMEs profiles of the extracted lipids during cultivation can be a manifestation of the microbial speciation phenomena observed by Mondala et al. [17] during lipid accumulation of activated sludge. The stress effect from the feeding of the acidsubstrates might be resulting to the death of microbes not adapted to the acid-substrates and culture media, and to the proliferation of species that can utilize the acids and adapt to the media conditions. This speciation may explain the change in the composition of the extracted microbial lipid.

\begin{tabular}{|c|c|}
\hline Treatment & Observed $\mathbf{Y}_{\mathbf{x} / \mathbf{s}}$ (g-biomass produced/g-substrate consumed) \\
\hline 1 & n.a. \\
\hline 2 & $0.238^{\mathrm{a}}$ \\
\hline 3 & $0.448^{\mathrm{a}}$ \\
\hline 4 & $0.509^{\mathrm{b}}$ \\
\hline 5 & $0.417^{\mathrm{a}}$ \\
\hline 6 & $0.177^{\mathrm{a}}$ \\
\hline
\end{tabular}

Table 2: Observed overall biomass yields from the fed-batch runs: "Not calculated since there are three acids and stationary phase was quickly reached; ${ }^{a} D a t a$ from 24 hour to $120 \mathrm{~h}$ period; 'Data from 36 hour to $108 \mathrm{~h}$ period. 
Citation: Fortela DL, Hernandez R, Zappi M, French TW, Bajpai R, et al. (2016) Microbial Lipid Accumulation Capability of Activated Sludge Feeding on Short Chain Fatty Acids as Carbon Sources through Fed-Batch Cultivation. J Bioprocess Biotech 6: 275. doi:10.4172/2155-9821.1000275

The fluorescence images (Figure 4) also confirmed the claim that feeding with acid-substrate can enhance the lipid content of activated sludge microorganisms. Also notable in the overlay images of fluorescence and transmitted light micrographs are the sizes of the lipid-droplet-containing microorganisms. Most of the round-shaped cells are large enough to be within the range of 3-10 micrometers while bacteria, which are the dominant consortia in raw activated sludge, are typically 1 -fold smaller. This suggests that other oleaginous microorganisms propagated during the cultivation. Considering the sizes of the observed cells, these oleaginous round-shaped microorganisms could be yeasts. Microbial community profiling is being conducted to study the dynamics of the microbial groups during cultivation. This work will be published elsewhere.

\section{Conclusions}

Activated sludge microbial consortia can accumulate microbial lipid by feeding on Short Chain Fatty Acids (SCFAs) such as acetic acid, propionic acid and butyric acid as carbon sources through fed-batch cultivation. Though all three acids can be utilized as carbon sources, acetic acid resulted in better performance with respect to biomass growth and lipid accumulation. Batch feeding of nitrogen results in significant lipid accumulation as compared to fed-batch feeding. Buffering of $\mathrm{pH}$ and regulating the acid-substrates loading also significantly affect lipid accumulation performance. The study also demonstrated that activated sludge feeding on acetic acid can accumulate lipids as well as oleaginous microorganisms. Fluorescence microscopy images suggest that the neutral-lipid containing microorganisms responsible for lipid accumulation on SCFAs are likely to be yeasts.

\section{Acknowledgements}

We would also like to thank Dr. Thomas Pesacreta of the Microscopy Center at the University of Louisiana at Lafayette for the assistance in taking the fluorescence micrographs.

\section{References}

1. Agler MT, Wrenn BA, Zinder SH, Angenent LT (2011) Waste to bioproduct conversion with undefined mixed cultures: the carboxylate platform. Trends Biotechnol 29: 70-78.

2. Kleerebezem R, van Loosdrecht MC (2007) Mixed culture biotechnology for bioenergy production. Curr Opin Biotechnol 18: 207-212.

3. Mondala A, Hernandez R, Holmes W, French T, McFarland L, et al. (2013) Enhanced microbial oil production by activated sludge microorganisms via cofermentation of glucose and xylose. AIChE Journal 59: 4036-4044.

4. Revellame E, Hernandez R, French W, Holmes W, Alley E (2010) Biodiese from activated sludge through in situ transesterification. J Chem Techno Biotechnol 85: 614-620.

5. Fei Q, Chang HN, Shang L, Choi JD, Kim N, et al. (2011) The effect of volatile fatty acids as a sole carbon source on lipid accumulation by Cryptococcus albidus for biodiesel production. Bioresour Technol 102: 2695-2701.

6. Fontanille P, Kumar V, Christophe G, Nouaille R, Larroche C (2012) Bioconversion of volatile fatty acids into lipids by the oleaginous yeast Yarrowia lipolytica. Bioresour Technol 114: 443-449.

7. Papanikolaou S, Aggelis G (2011) Lipids of oleaginous yeasts. Part I: Biochemistry of single cell oil production. Eur J Lipid Sci Technol 113: 10311051.

8. Chang HN, Kim NJ, Kang J, Jeong CM (2010) Biomass-derived volatile fatty acid platform for fuels and chemicals. Biotechnology and Bioprocess Engineering 15: 1-10.

9. Park GW, Fei Q, Jung K, Chang HN, Kim YC, et al. (2014) Volatile fatty acids derived from waste organics provide an economical carbon source for microbial lipids/biodiesel production. Biotechnol J 9: 1536-1546.

10. Fortela DL, Hernandez R, Zappi M, Holmes W, Revellame E, et al. (2014) Refining the concept of integrating anaerobic-aerobic microbial systems to produce chemicals and lipids for fuels. Proceedings of the AIChE Annual Meeting.
11. Mondala A, Hernandez R, French T, McFarland L, Sparks D et al. (2012) Effect of acetic acid on lipid accumulation by glucose-fed activated sludge cultures. $J$ Chem Technol Biotechnol 87: 33-41.

12. Fei Q, Chang H, Shang L, Choi JD (2011) Exploring low-cost carbon sources for microbial lipids production by fed-batch cultivation of Cryptococcus albidus. Biotechnology and Bioprocess Engineering 16: 482-487.

13. du Preez JC, Immelman M, Kilian SG (1996) The utilization of short-chain monocarboxylic acids as carbon sources for the production of gamma-linolenic acid by Mucor strains in fed-batch culture. World $\mathrm{J}$ Microbiol Biotechnol 12 : 68-72.

14. du Preez JC, Immelman M, Kock JLF, Kilian SG (1997) The effect of acetic acid concentration on the growth and production of gamma-linolenic acid by $\mathrm{Muco}$ circinelloides CBS 203.28 in fed-batch culture. World J Microbiol Biotechnol 13: 81-87.

15. Li Y, Zhao Z, Bai F (2007) High-density cultivation of oleaginous yeast Rhodosporidium toruloides $\mathrm{Y} 4$ in fed-batch culture. Enzyme and Microbia Technology 41: 312-317.

16. Meesters PAEP, Huijberts GNM, Eggink G (1996) High-cell-density cultivation of the lipid accumulating yeast Cryptococcus curvatus using glycerol as a carbon source. Applied Microbiology and Biotechnology 45: 575-579.

17. Mondala AH, Hernandez R, French T, McFarland L, Santo Domingo JW, et al. (2012) Enhanced lipid and biodiesel production from glucose-fed activated sludge: Kinetics and microbial community analysis. AIChE Journal 58: 12791290.

18. Awad MF, Kraume M (2011) Fungal diversity in activated sludge from membrane bioreactors in Berlin. Can J Microbiol 57: 693-698.

19. Shchegolkova NM, Krasnov GS, Belova AA, Dmitriev AA, Kharitonov SL, et al (2016) Microbial Community Structure of Activated Sludge in Treatment Plants with Different Wastewater Compositions. Front Microbiol 7: 90.

20. Dufreche S, Hernandez R, French T, Sparks D, Zappi M, et al. (2007) Extraction of lipids from municipal wastewater plant microorganisms for production of biodiesel. J Am Oil Chem Soc 84: 181-187.

21. Mondala A, Liang K, Toghiani H, Hernandez R, French T (2009) Biodiese production by in situ transesterification of municipal primary and secondary sludges. Bioresour Technol 100: 1203-1210.

22. Gaidis JM (2004) Chemistry of corrosion inhibitors. Cem Concr Compos 26 181-189.

23. Mondala A, Hernandez R, French T, Green M, McFarland L, et al. (2015) Enhanced microbial oil production by activated sludge microorganisms from sugarcane bagasse hydrolyzate. Renewable Energy 78: 114-118.

24. Revellame E, Hernandez R, French W, Holmes W, Alley E, et al. (2011) Production of biodiesel from wet activated sludge. J Chem Technol Biotechno 86: 61-68.

25. Revellame ED, Hernandez R, French WT, Holmes WE, Forks A, et al. (2013) Lipid-enhancement of activated sludges obtained from conventional activated sludge and oxidation ditch processes. Bioresour Technol 148: 487-493.

26. Chanona J, Ribes J, Seco A, Ferrer J (2006) Optimum design and operation of primary sludge fermentation schemes for volatile fatty acids production. Water Res 40: 53-60

27. Ucisik AS, Henze M (2008) Biological hydrolysis and acidification of sludge under anaerobic conditions: the effect of sludge type and origin on the production and composition of volatile fatty acids. Water Res 42: 3729-3738.

28. Fortela DL, Hernandez R, French WT, Mondala A, Holmes W, et al. (2013) Integration of anaerobic digestion of cellulose into lipid accumulation by a mixed microbial consortium. Proceedings of the AIChE Annual Meeting.

29. Ratledge C (1997) Microbial Lipids. In: Biotechnology: Products of Secondary Metabolism. Rehm HJ, Reed G (Eds). Wiley Interscience. 